\title{
The Asymmetric Power of Chiral Ligands Determined by Competitive Asymmetric
} Autocatalysis

\author{
François Lutz, Itaru Sato, Kenso Soai* \\ Department of Applied Chemistry, Faculty of Science, Tokyo University of Science, Kagurazaka, Shinjuku-ku, Tokyo 162- \\ 8601, Japan \\ soai@ rs.kagu.tus.ac.jp
}

\begin{abstract}
Asymmetric autocatalysis initiated by two competing pseudoenantiomeric ligands : typical experimental procedure
\end{abstract}
To a mixture of $(1 S, 2 R)-N, N$-dibutylnorephedrine $2 \mathbf{b}$ ( $>98 \%$ ee, $5.0 \mathrm{~mL}$ of a $10 \mathrm{mM}$ toluene solution, $0.050 \mathrm{mmol})$ and $(1 R, 2 S)-N, N$-dimethylnorephedrine $\mathbf{2 f}(>98 \%$ ee, $5.0 \mathrm{~mL}$ of a $10 \mathrm{mM}$ toluene solution, $0.050 \mathrm{mmol})$ was slowly added diisopropylzinc $(1.0 \mathrm{~mL}, 1 \mathrm{M}$ in toluene, $1.0 \mathrm{mmol})$ at $0{ }^{\circ} \mathrm{C}$. After stirring the mixture for $30 \mathrm{~min}$, a toluene solution $(3 \mathrm{~mL})$ of 2-tert-butylethynylpyrimidine-5-carbaldehyde $1(94 \mathrm{mg}, 0.50 \mathrm{mmol})$ was added drop to drop. After $3 \mathrm{~h} \mathrm{at} 0{ }^{\circ} \mathrm{C}$, the reaction was quenched with a $1 \mathrm{M}$ aqueous hydrochloride solution $(3 \mathrm{~mL})$ then a saturated aqueous $\mathrm{NaHCO}_{3}$ solution $(9$ $\mathrm{mL}$ ). The mixture was filtered on Celite and extracted by ethyl acetate. The combined organic layers were dried with $\mathrm{Na}_{2} \mathrm{SO}_{4}$ and evaporated under reduced pressure. Purification of the residue by silica gel TLC (developing solvent : hexane/AcOEt $=60 / 40)$ afforded $109 \mathrm{mg}(94 \%)$ of $(S)$-2-methyl-1-[2-(3,3-dimethylbut-1-ynyl)pyrimidin-5-yl]propan-1-ol 3 with $97 \%$ ee (determined by HPLC using a chiral column Chiralcel OD-H). 